\title{
Value of the ERG in congenital nystagmus
}

\author{
P A GOOD, A E T SEARLE, S CAMPBELL, AND S J CREWS
}

From the Birmingham and Midland Eye Hospital

SUMMARY A group of 64 children with poor vision and early onset nystagmus were investigated retrospectively by the electroretinogram (ERG). Fifty-eight of these children also underwent analysis of the visual evoked potential (VEP), and 40 underwent colour vision analysis. Seventeen children were found to have complete congenital achromatopsia (rod monochromatism), being identified by their total colour blindness, reduced visual acuity, and reduced or absent photopic and flicker $(30 \mathrm{~Hz})$ ERGs. Two children with incomplete X-linked congenital achromatopsia were also found. This study identified the need to investigate children with nystagmus by means of the ERG and suggested that the ERG was useful where the diagnosis was uncertain, particularly at early school age. The incidence of congenital achromatopsia in a group of otherwise undiagnosed children with early onset nystagmus was high ( $29 \%$ ), with $40 \%$ being classified as having congenital idiopathic nystagmus.

Nystagmus presenting in infancy, often referred to as congenital nystagmus, is a non-specific manifestation of a wide variety of disorders of the eyes, visual pathway, or central nervous system. ${ }^{12}$ The ophthalmologist is asked to assess the vision and identify any ocular causes. The diagnosis is straightforward when there are obvious abnormalities such as strabismus, aniridia, cataracts, or colobomata. However, there are a number of children where no gross eye anomalies can be found and there are no changes on general or central nervous system examination. In some of the children there may be a family history of nystagmus which may help with the diagnosis. ${ }^{3}$

Analysis of the type of nystagmus may give guidelines towards making the diagnosis. The 'searching' type is indicative of Leber's amaurosis or optic nerve diseases such as atrophy or hypoplasia, ${ }^{12}$ whereas the 'pendular' type of nystagmus is associated with ocular albinism, retinoschisis, achromatopsia, and congenital stationary night blindness (CSNB). ${ }^{12}$ Congenital idiopathic nystagmus (motor efferent) can often be identified by observing the point of reversal or null zone, together with any compensatory head posture, or the development of a jerky nystagmus on lateral gaze. ${ }^{1}$

Ocular albinism may be identified by iris transillumination and foveal hypoplasia, together with abnormalities in the visual evoked potential (VEP).

Correspondence to Mr P A Good, BSc, Birmingham and Midland Eye Hospital, Church Street, Birmingham B3 2NS.
The clinical signs of foveoschisis, CSNB, and achromatopsia are not consistently present. Variability of clinical signs is a feature of conditions associated with early onset nystagmus and can lead to incorrect diagnosis.

Complete congenital achromatopsia (rod monochromatism) is considered by most authors to be a rare condition, having a prevalence of $1-3$ per 100000 of the normal population. ${ }^{4}$ The most extensive study of this condition to date was carried out by François $e t$ al.,$^{5}$ who assessed 215 patients with congenital achromatopsia, and demonstrated an autosomal recessive inheritance.

More recently certain rare incomplete variants of congenital achromatopsia have been identified. In one of these variants the blue cones appear to be intact, the vision is fairly good, and nystagmus is minimal or absent; however, the electroretinogram (ERG) abnormalities are as severe as in complete achromatopsia. It is thought that this incomplete variant may be progressive, with an $\mathrm{X}$-linked recessive inheritance. ${ }^{6}$ Although a history of photophobia, and reluctance to play in bright daylight, together with a fine $\left(3^{\circ}\right)$ nystagmus, is indicative of congenital achromatopsia, ${ }^{3}$ these findings are by no means consistent. Many authors, notably Harcourt, ${ }^{7}$ have recommended the use of the ERG in order to identify the complete or incomplete forms of congenital achromatopsia.

This study examines the use of ERG analysis in 
classifying children who present with early onset nystagmus and suggests the value of obtaining such a classification for prognosis and genetic counselling.

\section{Patients and methods}

Sixty-four children or young adults ( $<18$ years) with early onset nystagmus were assessed. They represented all such patients referred for electrodiagnostic assessment from April 1984 to May 1988. Thirty-six of the children were male and 28 female.

Every patient underwent assessment of visual acuity, fundus examination, and ERG (scotopic, photopic, and $30 \mathrm{~Hz}$ flicker). Fifty-eight of the children underwent VEP analysis, and 40 were assessed for colour vision. Colour vision analysis was obtained by means of a Farnsworth Munsell (F/100) colour test. None of the children in this study had colour vision assessment by means of the Sloan test, ${ }^{8}$ which has been reported by some authors as being useful in the diagnosis of achromatopsia. Of the 17 children with complete congenital achromatopsia 10 received genetic counselling, and therefore a full study of the family history.

ERGs were obtained under scotopic and photopic conditions, using a stimulus of 1200 lux. Where possible the scotopic ERG was obtained after 10 minutes' dark adaptation. Photopic conditions were ensured by adapting the patient with a 650 lux Ganzfeld light source. The flicker ERGs were recorded with a $30 \mathrm{~Hz}$ white light stimulus of 975 lux. Recording electrodes were of a $\mathrm{Ag} / \mathrm{AgCl}$ electroencephalograph (EEG) type, and the active electrodes placed on the lower eyelids. Reference electrodes were placed on the outer canthus of either eye.

VEPs were recorded to flash stimulation only. Pattern reversal stimulation was thought to be inappropriate because it requires good fixation, which is negated by nystagmus. Two children were assessed by pattern reversal stimuli, and as their. responses were absent no further children were thus assessed. Recording electrodes were placed on scalp positions $\mathrm{Fz}$ and $\mathrm{Oz}$, according to the international EEG convention. Fz was connected to the positive side of the amplifier, such that all positive waves appeared in a downward direction.

The VEPs and ERGs were recorded using a Nicolet CA1000 clinical averager, and stimulus was provided by a Ganzfeld stimulator. VEPs and ERGs were analysed by peak to peak measurements of P2 waves and $b$ waves respectively.

\section{Results}

Table 1 shows the breakdown of the diagnoses obtained following electrodiagnostic assessment. The visual acuities in general were better in the children with idiopathic nystagmus than in those with complete congenital achromatopsia and Leber's amaurosis.

It can be seen from Table 2 that the ERGs were normal in the children with idiopathic nystagmus and ocular albinism. In Leber's amaurosis the ERGs were grossly abnormal to all stimuli. In the children with complete or incomplete congenital achromatopsia the scotopic ERGs were normal, and the photopic and flicker ERGs were grossly reduced or absent. Those with CSNB had ERGs with a short latency $a$ and $b$ wave to scotopic stimuli (similar to photopic ERG), and an abnormal a to $b$ wave ratio, sometimes referred to as the Schubert-Bornsheim change. The child with foveoschisis demonstrated an ERG with abnormal a to $b$ wave ratio to both scotopic and photopic stimuli (Fig. 1).

In seven of the eight children with ocular albinism the VEPs displayed contralateral enhancementthat is, the amplitude of the VEP was much greater from the hemisphere contralateral to the eye being stimulated than the VEP from the ipsilateral hemisphere. Four out of the seven children with Leber's amaurosis had reduced VEPs. The VEPs were normal in all the other groups of children.

Analysis of colour vision by the $F / 100$ test revealed gross abnormalities in all the children with complete achromatopsia, but the abnormalities in the two brothers with incomplete achromatopsia were only mild, with a blue-yellow axis.

The family histories of the 17 children with complete congenital achromatopsia suggested an autosomal recessive inheritance in every case. Ten of the children presented with no known family history, five were male and five female. The other seven children with complete achromatopsia came from three families. One family included two affected girls and one affected boy, and the other two families each included one affected male and one affected female. Parental consanguinity was found in only two families, which is in contrast to the findings of François et al. ${ }^{5}$ and Bell, ${ }^{9}$ who reported parental consanguinity in $20-30 \%$ of families. The two children with suspected incomplete achromatopsia, were brothers, with no other family history, which was therefore consistent with an X-linked recessive inheritance.

All but one of the children with complete achromatopsia were attending normal schools without difficulty, and the two boys with the incomplete form were also attending normal schools. The one patient (aged 18) who had attended a school for the partially sighted stated that she was not as visually handicapped as her fellow pupils, and she considered this 
Table 1 Final diagnoses of children with congenital nystagmus in this study. Fundus, visual acuity, and inheritance

\begin{tabular}{|c|c|c|c|}
\hline Diagnosis & Visual acuity & Fundus appearance & Inheritance \\
\hline $\begin{array}{l}\text { Congenital achromatopsia }(n=17) \\
\text { Incomplete congenital achromatopsia } \\
\quad(n=2)\end{array}$ & $\begin{array}{c}6 / 36-1 / 60 \\
6 / 18-6 / 24 \\
\end{array}$ & $\begin{array}{l}\text { Normal, occasional macular hyperpigmentation } \\
\text { Normal }\end{array}$ & $\begin{array}{l}\text { Autosomal recessive } \\
\text { ? X-linked recessive }\end{array}$ \\
\hline $\begin{array}{l}\text { Congenital stationary night blindness } \\
(\mathrm{n}=1)\end{array}$ & $6 / 18$ & Normal & $\mathrm{X}$-linked recessive \\
\hline Ocular albinism $(n=8)$ & $6 / 18-6 / 36$ & Foveal hypoplasia (iris transillumination) & $\mathrm{X}$-linked recessive \\
\hline Leber's amaurosis $(n=7)$ & $6 / 36-<1 / 60$ & $\begin{array}{l}\text { Optic disc pallor, narrow vessels, and/or peripheral or } \\
\text { macular pigmentation. Two patients described as normal }\end{array}$ & $\begin{array}{l}\text { Mainly autosomal } \\
\text { recessive }\end{array}$ \\
\hline $\begin{array}{l}\text { Juvenile retinoschisis }(n=1) \\
\text { Congenital idiopathic nystagmus }(n=28)\end{array}$ & $\begin{array}{l}6 / 18 \\
6 / 18-6 / 60\end{array}$ & $\begin{array}{l}\text { Foveoschisis, vitreous opacities } \\
\text { Normal }\end{array}$ & $\begin{array}{l}\text { X-linked recessive } \\
\text { X-linked dominant }\end{array}$ \\
\hline
\end{tabular}

to be a disadvantage. She was previously diagnosed as having congenital idiopathic nystagmus.

\section{Discussion}

The results of this study confirm that the ERG using scotopic, photopic, and flicker stimuli is of value in classifying children and young adults with early onset nystagmus. This test is of particular value in differentiating between idiopathic nystagmus and complete or incomplete congenital achromatopsia, the absence or gross reduction of photopic and flicker ERGs being diagnostic in the latter conditions.

$29 \%$ of the children in this study, who presented with unclassified early onset nystagmus, were after ERG analysis classified as having congenital achromatopsia. Although the result of colour vision analysis was fairly typical of complete achromatopsia in this study, other authors have questioned the reliability of such techniques in identifying the condition. This has been partly resolved by the use of the Sloan colour test. ${ }^{8}$ However, many children are unreliable in subjective testing. An objective measurement such as the ERG is therefore of value and can be performed quickly and painlessly. Nevertheless colour vision testing remains an invaluable indicator of the incomplete forms of achromatopsia. The ERG also proves to be of value in the differential diagnosis of Leber's amaurosis (gross reductions to all stimuli) and in CSNB (Schubert-Bornsheim ERG). Analysis of the ERG waveform can also identify foveoschisis.

The VEP to flash stimulation would appear to be of value in cases of ocular albinism, and the finding of

Table 2 Test results

\begin{tabular}{|c|c|c|c|c|c|c|}
\hline \multirow[t]{2}{*}{ Diagnosis } & \multirow[t]{2}{*}{ Age (years) } & \multirow{2}{*}{$\begin{array}{l}\text { Colour vision } \\
(F / 100)\end{array}$} & \multirow{2}{*}{$\begin{array}{l}V E P \text { (flash) } \\
\text { (amplitude) }\end{array}$} & \multicolumn{3}{|l|}{$E R G$} \\
\hline & & & & Scotopic & Photopic & Flicker \\
\hline Congenital achromatopsia & $\begin{array}{l}2-18 \\
x=11 \cdot 3\end{array}$ & $\begin{array}{r}534-850 \\
x=608 \cdot 4\end{array}$ & $\begin{array}{l}6-24^{*} \\
x=12 \cdot 4\end{array}$ & $\begin{array}{l}\text { 43-102* } \\
x=68 \cdot 3\end{array}$ & $\begin{array}{l}2-8^{*} \\
x=3 \cdot 8\end{array}$ & $\begin{array}{l}0-2 * \\
x=0.6\end{array}$ \\
\hline Incomplete congenital achromatopsia & $\begin{array}{l}9-10 \\
x=9 \cdot 5\end{array}$ & $\begin{array}{l}234-268 \\
x=251 \cdot 0\end{array}$ & $\begin{array}{l}12-16 \\
x=14 \cdot 0\end{array}$ & $\begin{array}{l}67-96 \\
x=81 \cdot 5\end{array}$ & $\begin{array}{l}3-7 \\
x=5 \cdot 0\end{array}$ & $\begin{array}{l}0-0.5 \\
x=0.25\end{array}$ \\
\hline Congenital stationary night blindness & 14 & - & $\begin{array}{l}11-12 \\
x=11 \cdot 5\end{array}$ & $\begin{array}{l}14-18 \dagger \\
x=16 \cdot 0\end{array}$ & $\begin{array}{l}22-23 \\
x=22 \cdot 5\end{array}$ & $\begin{array}{l}12-13 \\
x=12 \cdot 5\end{array}$ \\
\hline Ocular albinism & $\begin{array}{l}3-17 \\
x=7 \cdot 5\end{array}$ & $\begin{array}{l}86-112 \\
x=97 \cdot 0\end{array}$ & $\begin{array}{c}8-15 \ddagger \\
x=12 \cdot 8\end{array}$ & $\begin{array}{l}49-115 \\
x=77.4\end{array}$ & $\begin{array}{l}28-64 \\
x=39 \cdot 3\end{array}$ & $\begin{array}{l}12-21 \\
x=17 \cdot 2\end{array}$ \\
\hline Leber's amaurosis & $\begin{array}{l}1-10 \\
x=4 \cdot 6\end{array}$ & - & $\begin{array}{l}2-14 \\
x=6 \cdot 8\end{array}$ & $\begin{array}{l}0-2 \\
x=0.8\end{array}$ & $\begin{array}{l}0-4 \\
x=1 \cdot 2\end{array}$ & $\begin{array}{l}0-5 \\
x=2 \cdot 3\end{array}$ \\
\hline Juvenile retinoschisis (foveoschisis) & 12 & 328 & $\begin{array}{l}4-5 \\
x=4 \cdot 5\end{array}$ & $\begin{array}{l}10-20 \S \\
x=15 \cdot 0\end{array}$ & $\begin{array}{l}11-16 \S \\
x=13 \cdot 5\end{array}$ & $\begin{array}{l}4-7 \\
x=5 \cdot 5\end{array}$ \\
\hline Congenital idopathic nystagmus & $\begin{array}{l}2-18 \\
x=8 \cdot 4\end{array}$ & $\begin{array}{l}67-178 \\
x=105 \cdot 0\end{array}$ & $\begin{array}{l}6-28 \\
x=12 \cdot 5\end{array}$ & $\begin{array}{r}45-97 \\
x=68 \cdot 7\end{array}$ & $\begin{array}{l}16-43 \\
x=26 \cdot 8\end{array}$ & $\begin{array}{l}5-14 \\
x=9.6\end{array}$ \\
\hline
\end{tabular}

$x=$ Mean.

*Normal range for $\mathrm{VEP}=4-35 \mu \mathrm{V}$.

Normal range for scotopic lid $E R G=30-130 \mu \mathrm{V}$.

Normal range for photopic lid $E R G=15-65 \mu \mathrm{V}$.

Normal range for flicker lid $E R G=5-18 \mu \mathrm{V}$.

†Schubert-Bornsheim change.

$\ddagger$ Most of these VEPs displayed contralateral enhancement of the P2 component, indicating misrouting of the visual pathways.

§Abnormal a to b wave ratio.

$\mathrm{F} / 100$ values are in terms of 'total error score'. 


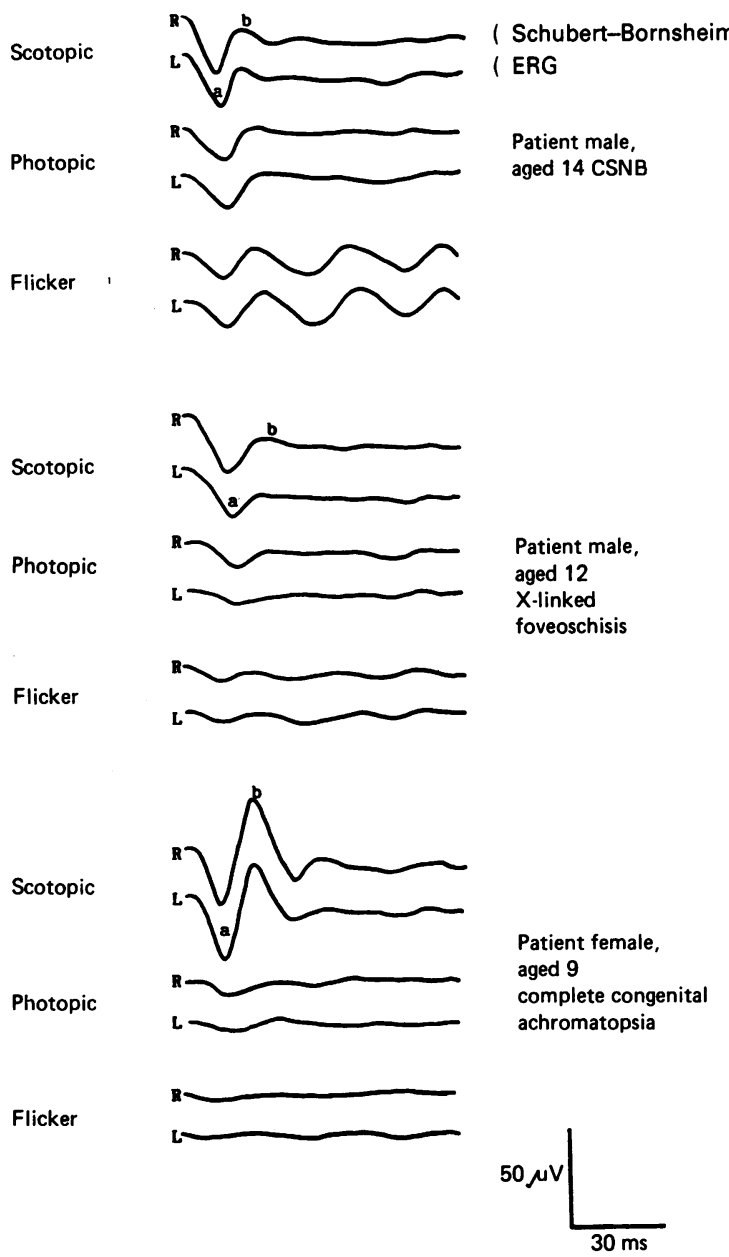

Fig. 1 ERG abnormalities in CSNB (shortened scotopic a and $\mathrm{b}$ wave, and abnormal a to $\mathrm{b}$ wave ratio), $X$-linked foveoschisis (abnormal a to $\mathrm{b}$ wave ratio), and congenital achromatopsia.

a normal flash VEP in children with congenital achromatopsia is interesting, particularly as the visual acuity was frequently less than $6 / 60$. The use of pattern reversal stimulation is questionable, since nystagmus makes accurate fixation difficult. However, such a stimulation may be a help to diagnosis in those children suspected of psychogenic visual loss.

Interestingly most children referred for investigation were of school age and many were in secondary school or had just left school. Only two children in the complete achromatopsia group were under 5 years old. It was apparent that the reason for referral was for diagnosis, so that advice on prognosis, future schooling and career, and inheritance risks could be given. There would appear to be a need for classification of early onset nystagmus within the first few years of schooling. Decisions on education, and appropriate measures such as aids to low vision glasses, ${ }^{8}$ could be introduced at an early age .

The probability that complete congenital achromatopsia is more common than has been previously suggested is a further indication that all children with early onset nystagmus should be investigated more thoroughly, particularly with the ERG.

We thank Miss $\mathbf{K}$ Levell and Mr $\mathbf{J}$ McLoughlin for technical assistance, and $\mathrm{Mr} \mathrm{H} \mathrm{E}$ Willshaw for reading the manuscript.

\section{References}

1 Carr RE. Electrodiagnostic tests of the retina and higher centres. In: Harley, RB, ed. Pediatric ophthalmology. 2nd ed. Philadelphia, Saunders 1983: 189-206.

2 Verriest G. Les déficiences de la vision de couleurs. Bull Soc Ophtalmol Fr 1969; 69: 901-9.

3 Krill AE. In: Krill AE, Archer DB, eds. Hereditary retinal and choroidal diseases. New York: Harper and Row, 1977; 2: 359-70.

4 Pearce WG. Causes of blindness in children: 1046 cases registered with the Canadian Institute for the Blind 1970-1973. Can J Ophthalmol 1975; 10: 469-72.

5 François J, Verriest G, De Rouck A. L'achromatopsie congénitale. Doc Ophthalmol 1955; 9: 338-424.

6 Fleishman JA, O'Donnell FE. Congenital X-linked incomplete achromatopsia. Arch Ophthalmol 1981; 99: 468-75.

7 Harcourt B. Hereditary nystagmus in early childhood. $J$ Med Genet 1970; 7: 253-6.

8 O'Connor PA, Tredici JT, Ivan DJ, Mumma JV, Shacklett DE. Achromatopsia: clinical diagnosis and treatment. J Clin Neuroophthalmol 1982; 2: 219-26.

9 Bell J. The treasury of human inheritance. London: Cambridge University Press, 1926: 2 (2): 125-267.

Accepted for publication 18 November 1988. 